\title{
The Reality of Life During Floods
}

\section{Luke Kuźmiński ${ }^{1 *}$, Luke Szałata ${ }^{2}$ and Jerzy Zwoździak ${ }^{3}$}

${ }^{1}$ Wroclaw University of Economics, UI. Komandorska 118/120, 53-345 Wroclaw, Poland

${ }^{2}$ Wroclaw University of Technology, PI. Grunwald 9, 50-377 Wroclaw, Poland

3IMGW-PIB Warsaw Branch, UI. Podleśna 61, Warsaw, Poland

\begin{abstract}
The aim of the article is to assess the variability of the risk of flood risk with the use of distributions maximum values. The copyright research is hydrological data in the form of daily water levels from the period 1981-2011. The collected data are derived from the hydrological station Bystrzyca Klodzka for the Nysa Klodzka river and the hydrological station Lesna for the Kwisa river. For the purpose of estimating flood risk from the collected data has been selected quarterly maxima of daily water levels. As a measure of the flood risk authors accepted the likelihood of exceeding the alarm condition in the test sections of the rivers. This risk is calculated by using the theoretical cumulative distribution distribution of quarterly highs water levels. The study was used Gumbel distribution. At the same time the article was paid significant attention to the possibility of using the solutions for integrated flood risk management process in accordance with applicable national legislation and European.
\end{abstract}

Keywords: Block method; Environmental risk management; Flood; Flood risk; Gumbel distributnion; Odra basin

\section{Introduction}

In order to more broadly understand the complex nature of the course of floods in some cases a closer description of the Kłodzka land as an area in south-western Poland in Central and Eastern Sudetes was made. It is characterized by varying morphology of the terrain and by its hydrographic network. The main drainage river for the Kłodzka Area is the Nysa Kłodzka together with its larger tributaries: the Biała Lądecka, the Bystrzyca Dusznicka and the Ścinawka. Due to large declines of river banks and river beds as well as high density of valley floors the reception the basin of the Nysa Kłodzka quickly responds to heavy rain with violent floods and high flows. Major floods do not last longer than two or three days and small ones - from a few to several hours [1].

\section{Purpose and scope of the article}

The primary objective of this article is to analyse the dynamics of the flood risk in the function of time and space on selected receptor basin areas. Given this, the authors of this article ask themselves a question in terms of the reality of life in floods and identify effective operational tools of technical and non-technical nature which will enable a more realistic prediction of the flood phenomena and contribute to the effective reduction of the socio-economic impact of the flood risk occurrences.

\section{Characteristics of Flooding in the Oder Basin}

The Oder river basin is highly developed and extremely asymmetrical. The reception basins of the left-side tributaries, the source areas of which are located in the Sudetenland and Sudeckie as well as Olza which flows from the Silesian Beskid, are all categorised as mountain-lowland rivers. There are three main types of landscape: the mountain and piedmont, upland and lowland. The differentiation of the environment of this area affects not only the amount of rainfall, but also the speed of the water run-off and the retention capabilities of the reception basin.

July and August are the months with a high risk of flooding on the Oder. This is confirmed by the hydrological data available in the database of the Institute of Meteorology and Water Management. To confirm the rank and scale of the flood risk and in accordance with historical data for the years 988-1774, chronicles recorded 36 major floods in the Oder river basin. In the nineteenth century, catastrophic floods occurred in the years: 1813, 1854, 1855 and 1888 . However, in the twentieth century a series of severe floods took place, among others in the years: 1903, 1915, 1924, 1938, 1940, 1947, 1958, $1960,1963,1964,1965,1970,1972,1977,1980,1985$, and 1997. The biggest flood of unprecedented size, exceeding the most catastrophic assessment, occurred in July, 1997. The second that flood in magnitude happened also in July, but in 1903 and was considered the biggest flood of the twentieth century until July 1997. Events of 2010 became the confirmation of the reproducibility of flood events. It should also be noted that the percentile ratio of the length of the Oder river in relation to the length of the individual tributaries is confirmed by the significant preceding of the culmination of the tributaries in contrast to the Oder observed in the event of natural water swells. The smallest preceding of the culmination is observed in the Nysa Kłodzka river. This preceding slightly reduces the amount of water in the Otmuchów and Nysa reservoirs, which is caused by the prolonging of a part of the falling wave on Nysa Kłodzka.

The likelihood of catastrophic floods occurring in the upper, middle and lower Oder is very small. In the lower reaches of the Oder river, there are usually spring floods, often related to the procession of ice. They can also occur in the time of not favourable storms on the Baltic Sea that hinder the flow of the flood water into the sea, which is confirmed by recorded peak flows during floods on the Oder river and the levels.

To make the flood risk more real, in 1598, torrential rains caused a significant landslide of the Bardzka Mountain slopes in Bardo and a partition of Nysa Kłodzka which flooded the city and then changed its river-bed. In 1997, during the "Flood of the millennium" a 9 meter high wave swept through the river and flooded Kłodzko. Storage reservoirs did not protect also Nysa from flooding. Throughout the Kłodzko Valley the rivers belonging to the Nysa Kłodzka basin caused huge damages. Long-term average flow at the mouth of the Nysa Kłodzka

*Corresponding author: Luke Kuźmiński, Wroclaw University of Economics, UI. Komandorska 118/120, 53-345 Wroclaw, Poland, Tel: +48 601181 398; E-mail: lukasz.kuzminski@ue.wroc.pl

Received July 27, 2016; Accepted August 03, 2016; Published August 05, 2016

Citation: Kuźmiński L, Szałata L, Zwoździak J (2016) The Reality of Life During Floods. J Civil Environ Eng 6: 249. doi: 10.4172/2165-784X.1000249

Copyright: @ 2016 Kuźmiński L, et al. This is an open-access article distributed under the terms of the Creative Commons Attribution License, which permits unrestricted use, distribution, and reproduction in any medium, provided the original author and source are credited. 
flowing into the Oder is $50 \mathrm{~m}^{3} / \mathrm{s}$, the flow that does not cause losses in the infrastructure below the dam is dependent on the swell of the Oder and varies between 150-190 $\mathrm{m}^{3} / \mathrm{s}$, while in July 1997 this flow was over $1500 \mathrm{~m}^{3} / \mathrm{s}$. Then, the emergency dump of Nyskie Lake flooded, among others: Nysa, Lewin Brzeski as well as numerous villages in the basin of the river and contributed to a significant increase of the water levels in the Oder, which flooded Wrocław [1]. In this paper, the authors focused their attention especially on the Upper Oder River Basin, taking into account the available water levels for Kwisa and Nysa Kłodzka rivers.

\section{The Occurrence of the Flood Risk in terms of Water Management}

The directions of water management, including the flood protection system as well as the reduction of the flooding system are defined by the national and European legislation on the broadly understood environmental protection. Appropriate references can be found in the program documents laid down in the Ministry of the Environment, such as The National Environmental Policy or environmental protection and sustainable development strategies. The directions of cooperation in the field of water management are also determined by international agreements concluded by the government or the Minister of the Environment both, the ratified ones as well as the bilateral agreements that do not require ratification. Offices of government together with lower level offices support the implementation of tasks in so far as they relate to their competences. By definition, "the socio-economic development, in which in order to balance access opportunities of individual communities or their citizens - both contemporary and future generations - to the environment, a process of integration of political, economic and social actions takes place maintaining the natural balance and the permanence of basic natural processes" and the area of operation of sustainable development shows that there is a need for the conservation of nature and the improvement of the natural environment's state. Continuing the development of a given region requires constant raising of social awareness in this respect, particularly, indicating the interdependence between the sustainable development and the economic interests [2].

The principle of sustainable development is written down in the Article 5 of the Polish Constitution. The sustainable development and the environmental protection constitute an important element of social and economic policies and the spatial development of the country [2].

The water management, in accordance with the Polish Water Law, as well as the Water Framework Directive and the Flood Directive, takes place in the hydrographic system, that is, in the river basins and water regions. The socio-economic aspect, in which the activities related to the natural balance and to the permanence of basic natural processes are integrated in order to guarantee the possibility of satisfying the basic needs of individual communities or citizens of both the present and future generations plays a very important role in achieving sustainable development. The Water Law of 18 July 2001 requires conducting water management in accordance with the principle of sustainable development concerning, in particular, the development of water resources protection as well as water use and water management. Water management is conducted according to the principle of rational and holistic treatment of surface and groundwater resources, including their quantity and quality, respecting the principle of common interests. It is implemented by the cooperation of the public administration, water users and representatives of local communities, so as to obtain the maximum social benefits, including economic and ecological ones. The application of the principle of sustainable development in water management and flood protection systems means striving for such a way of meeting the needs associated with the use of water resources so as not to curtail the access to them for future generations, while, at the same time, protecting the aquatic and water-dependent ecosystems in order to protect and preserve the stability of natural processes. Currently, the process of implementing these principles by the provisions of the Water Law, which covers the regulations of the Water Framework Directive and Flood Directive in this respect, is taking place. The actions being undertaken lead to the spread of an integrated approach to water management as well as the implementation of the flood protection system and methods for flood risk mitigation. While discussing the socio-economic functioning of the water management one should also pay special attention to the measurable socio-economic impact of the flooding and flood risk. At this point the following activities should be mentioned:

- Banning the construction of public facilities such as hospitals, schools, kindergartens, nursing homes and others of a similar nature.

- Banning the placing of facilities, such as sewage treatment plants, municipal waste landfills, toxic waste landfills, and chemical warehouses etc., which, in the case of flooding, pose a secondary risk.

- Allowing the construction of residential and public buildings, provided that their utility premises (e.g. residential premises) are located above the reliable flood level (i.e. the hundred year flood level), e.g. on an embankment, or that they are secured by encircling them with protective constructions or embankments (www.wroclaw.rzgw. gov 2016).

At this point, the description of this chapter should focus on the activities related to avoiding the social or economic indicators of the system's vulnerability such as the awareness of the flood risk or the degree of preparation for the coming of a flood all of which could be a source of significant damages. For example, according to German data, preparing the lower storey of a detached house to flooding reduces the damage by, between 5-30\%, while according to the Flood Hazard Research Centre from the US, reducing the time of warning the residents of impending floods results in reducing the damages by up to $10 \%$, with a range of reduction depending on the depth of flooding.

Modelling the flood risk by the use of probability distributions of selected hydrometric parameters as risk measures constitutes a practical tool for the evaluation of the actual financial risk in the insurance field for floodplains.

In summary, flood damages refer to a wide range of influences during the course of a flood in terms of their impact on:

- People, their health and property,

- Municipal infrastructure (water supply systems, waste disposal systems, transportation systems, power systems, etc.),

- Cultural heritage,

- Ecological systems,

- Industrial production,

- The competitiveness of the flood-affected businesses.

Depending on the manner of categorising, they are divided into material damages - expressed in monetary units and non-material damages - expressed in natural units, e.g. The number of casualties or the amount of square meters of the ecosystem flooded with sewage.

Therefore, the evaluation and assessment of hazards and flood risks 
and a proper reaction as well as the reduction of the potential flood damages in the described aspects is given a high priority in this respect.

\section{Applications of Extreme Value Theory in Hydrology - A Literature Review}

Historically, the year 1709 marks the beginning of working on the analysis of the extreme values problems. Then, Nicolas Bernoulli led reflections on the average largest distance between given $\mathrm{n}$ data points spread randomly on a straight line with a fixed length ' $t$ ' [3]. Very rich and comprehensive bibliography of the literature on the theory of extreme value distributions and their applications consists of more than 1,100 positions counting until the beginning of the 21 st century. There is no way to present them all as it would require a separate multi-volume monograph devoted solely to the subject study. Such a vast literature indicates a great interest in this field of science as well as its wide application. Therefore, in this chapter, only selected items will be presented that, in the author's opinion, had a significant impact on the development of the theory and that are closely related to the issues raised in the article. Obviously, such a rich literature in one area has also its drawbacks. The main problem is the lack of coordination between researchers in this field and the inevitable duplication (and even tripling) of the results appearing in various publications around the world. Probably, the first one to use the extreme values in studying floods in his article was Fuller in 1914). The systematic development of a general theory of extreme values, however, is associated with the work of Bortkiewicz, which concerned the distribution range in a random sample from a normally distributed population. This work is very important, since the author introduced and clearly defined the concept of distribution of the highest value there for the first time [4]. Gumbel first drew the attention of engineers and statisticians on the possibility of use the formal theory of extreme values for certain distributions that were previously regarded as empirical. He applied the distribution of extreme value to the analysis of stream flows in the USA in 1941 [5]. In subsequent works he continued his research and discussions on the estimation of extreme stream flows and flood forecasts [6-8]. In the course of his research, Teodorovic acquired the observed frequencies $\mathrm{N}(\mathrm{T})$, meaning the number of days in a period which was T days long, when the water flow in the Greenbrier river in West Virginia exceeded 17000 cubic feet. The period of his observation took 72 years, from 1896 to 1967 . He then compared the observed frequency with the theoretical Poisson distributions. In the results it could be seen that the discrete observations $\mathrm{N}(\mathrm{T})$ for the studied river and for the given climate can be very well modelled with Poisson distributions [9]. In the 70s - 90s of the twentieth century, a lot of papers were written on the subject of applying elements of the extreme value theory to solve problems associated with floods. Pericchi and Rodriguez-Iturbe conducted research based on data on daily water flows in the Feather river in Oroville, California, USA. The data collected came from the years 1902-1960. From these data, they selected to annual flow peaks and fitted their empirical distribution $t$ Gumbel distribution. In addition to that, in their work they proposed schedules such as: gamma (Person type III), gamma-log (log - Pearson type III) and log - normally for the analysis of selected peaks. In their research they also suggest the use of distribution function for overflows and gambling function for flood risk analysis [10]. The use of probability distributions for the flood frequency estimation was also illustrated in Greis' and Wood's work [11]. Shen applied the probability distributions to forecast flood events [12]. Rossi proposed a two-component extreme value distribution to analyse the frequency of flooding [13]. In subsequent years, Smith, Jain and Singh as well as Ahmad brought a discussion on the application of type I extreme value distribution to analyse the frequency of flooding
$[14,15]$. At the end of the twentieth century, after the great flood in the USA, which caused huge losses in the Midwest of the country, Hipel presented the use of extreme value theory in the analysis of flood events in his work. He accurately presented the analysis of emergency level exceedings over the span of 100 years in the context of the flood of 1993 [16].

The beginning of the 21 st century is also rich in terms of studies of hydrological and meteorological phenomena using the extreme value theory.

In their article, Katz with co-authors presented a comprehensive study using distributions of extreme values on hydrological data collected in Fort Collins, Colorado, USA [17]. Engeland, Frigessi and Hisdal presented the analysis of flood and drought risks using the generalized extreme value distributions and Pareto. They conducted their research on data concerning streamflows on the Ha river in south-west of Norway [18]. In their work, Bordi, along with coauthors, analysed wet and dry periods in Sicily. For this purpose they applied monthly rainfall maxima [19]. Yurtal and others compared in their work the method of maximum likelihood to weighted method of moments for estimating the parameters of hydrological data distributions probability obtained from measuring stations on the Ceyhan river in southern Turkey [20]. After a great number of floods in the Czech Republic, Holičky and Sykora used a log-normal distributions and Persona III in their research to estimate the flood risk for cultural heritage [21]. Nachabe and Paynter conducted research using generalized distribution of extreme values on hydrological data from the selected lakes in the south-west of Florida [22]. Chaibandit and Konyai, in their studies, analysed hydrological data obtained on a monthly basis from 6 stations on the Yom river. The study used the distributions of extreme values, normal distribution and log-normal distribution as well as the return period method [23]. Arns and others, in their studies, estimated the flood risk by estimating the probability of achieving a certain water level in rivers [24]. Charon, along with other scientists in their work compared a very large number of probability distributions used to model wind speeds. The data came from 9 meteorological stations in The United Arab Emirates [25].

The above presented overview of the applications of the extreme values theory constitutes only selected items that relate to the phenomena of floods. Additionally, it should be mentioned, that there exists a very large number of publications dealing with the use of extreme value theory to model many other meteorological phenomena as well as phenomena in the field of economics, engineering and many others. Due to the limited scope of this publication this point will mark the end of the chapter on application literature review.

\section{Selected Issues of the Theory of Extreme Values Distribution}

This chapter contains selected issues concerning the distribution of extreme values, which were used to carry out the research for this study. Issues covered in this chapter include: selected probability distributions of the maximum values along with the methods of parameter estimation and compliance tests, methods for visual representation of empirical distributions and the block method used to select the maximum values of specified data blocks.

\section{Maxima}

We assume that the $y_{i}$ observations are the maxima, i.e., that,

$y_{i}=\max \left\{x_{i 1}, \ldots, x_{i m}\right\}, i=1, \ldots, n$, 
Where $\mathrm{x}_{\mathrm{ij}}$ may not be observable. In the case where $\mathrm{x}_{\mathrm{ij}}$ are observable, the selection of certain maxima from certain sets with $m$ number of elements is a form of selection of the upper extreme values from a data set. This method is called the block method or the Gumbel method [26].

The block maxima method requires defining the time horizon (the block), and calculating the maxima of the tested variable for the said horizon. Most commonly, blocks of one year, half a year, quarter, month or smaller size are used depending on research needs. For data in the form of hydrometric parameters blocks of the mentioned above size are used. The block size cannot be too small to prevent the occurrence of the relationship between the maximum values of the neighbouring blocks of time. 10 day period is considered to be the minimum limit value of the size of the time block for which the independence of neighbouring maxima can be accepted.

There can also be cases when, during the long-lasting floods, there may occur a risk of a dependence even between the maxima of adjacent blocks of time. In such situations, when such a relationship between the variables under consideration occurs it is necessary to apply the cumulative distribution of extreme values for dependent random variables for the analysis of the distribution of the maximum values [27].

At this point, one more fact deserves attention, namely, that the observations $y_{i}$ are the embodiments of the random variable $M_{m}$ defined by the formula:

$$
M_{m}=\max \left\{X_{1}, \ldots, X_{m}\right\}
$$

\section{Probabilistic models of maxima values}

In the probabilistic studies of maxima distributions for hydrometric data it is suggested to first apply the Gumbel distribution, which is one of the three types of extreme value distributions [28]. The [IACWD (US Interagency Advisory Committee on Water Data - Hydrology Subcommittee) 1983] report recommends the Persona III distribution with the log-normal transformation for long-term data to predict flood events as well as the log-normal distribution.

According to the theorem concerning the types of extreme value distributions [29] the distributions of extreme values are one of three distribution functions described by the following formulas:

$$
\begin{aligned}
& \text { Gumbel (EV0 lub Typ I): } \quad G_{0}(x)=\exp \left(-e^{-x}\right), \quad-\infty<x<\infty \\
& \text { Frechet (EV1 lub Typ II): } \quad G_{1}(x)=\exp \left(-x^{-\alpha}\right), \quad \text { dla pewnego } \alpha>0, \quad x>0 \\
& \text { Weibull (EV2 lub TypIII): } G_{2}(x)=\exp \left(-(-x)^{\alpha}\right), \text { dla pewnego } \alpha>0, \quad x \leq 0 .
\end{aligned}
$$

The family of distribution functions of the maxima distributions specified in the (3) formula can be extended by introducing the parameterization to distribution function's formulas expressed with the above formula. The location parameter $\mu$ and the scale parameter $\sigma$ are introduced into the formulas of the distribution functions. The transformation based on adding the above-mentioned parameters takes place according to the Theorem 1 .

Theorem 1: If the random variable $\mathrm{X}$ has distribution function $\mathrm{F}$, then the random variable $(\mu+\sigma \mathrm{X})$ has the distribution function $F_{\mu, \sigma}(x)=F((x-\mu) / \sigma)[26]$.

After the parameterization according to Theorem 1, distribution functions expressed with the formula (3) take the following form:

EV0Model: $G_{0, \mu, \sigma}(x)=\exp \left(-e^{-(x-\mu) / \sigma}\right)$

EV1 and EV2 Models:

$$
G_{i, \alpha, \mu, \sigma}(x)=G_{i, \alpha}\left(\frac{x-\mu}{\sigma}\right), i=1,2 .
$$

The above parameterization of the family of distribution functions of the maximal values significantly broadens the spectrum of possibilities related to modelling of the distributions of maximal values of various random variables. By utilizing the parameterized distribution functions of maximal values one can very precisely choose a theoretical distribution function which satisfactorily describes the distribution of the value of the given maximal characteristics.

Concluding the topic of the family of distribution functions of extreme values it should be mentioned that all distribution functions presented in formulas (3) and (4) as members of one family of distributions described by the formula: $[18,30]$.

$$
G_{\gamma, \mu, \sigma}(x)= \begin{cases}\exp \left\{-\left[1+\gamma\left(\frac{x-\mu}{\sigma}\right)\right]^{-\frac{1}{\gamma}}\right\} & \text { if } \gamma \neq 0 \\ \exp \left\{-\exp \left(\frac{x-\mu}{\sigma}\right)\right\} & \text { if } \gamma=0\end{cases}
$$

In examining the empirical distributions of the maximal values of hydrological characteristics one should be aware of the normal distribution. There are situations when empirical distributions of the maximal values of the studied characteristics are more consistent with the Gaussian distribution then with the distributions expressed with the formula (4).

In the research that was conducted for this article a tool in the form of empirical density function of the probability distribution, also called kernel density, was used to visualise empirical distributions of the maximal values of specific hydrological characteristics. This precise form of an empirical histogram is described with the formula [27]:

$$
f_{n, b}(x)=\frac{1}{n b} \sum_{i \leq n} k\left(\frac{x-x_{i}}{b}\right),
$$

Where $\mathrm{k}$ is the function (kernel), such that $\int k(y) d y=1$ and $\mathrm{b}>0$ is the desired bandwidth. The functionalkhas several forms defined which are used. In this study, the functional $k(x)=0,75\left(1-x^{2}\right) I(-1 \leq x \leq 1)$ was used

\section{Estimation methods and tests of significance}

In this study, for the purpose of the conducted research, the highest reliability method was applied to estimate the distribution parameters of the maximal values of the family of distributions described with the formula (4). This method gives effective results in specific cases. These cases concur with the cases considered in this study [30,31]. The parameter $\gamma$ estimator exists for $\gamma>-1$ and for $\gamma>-0.5$ the variance has asymptotically normal distribution [14].

In order to verify the hypotheses concerning the compatibility of the studied empirical distributions with the selected theoretical distributions of maximal values described in the paper the following compliance tests were applied: chi - square test, Kolmogorov - Smirnov test and Anderson - Darling test.

In addition, within the family of distributions of extreme values described by the formula (5) the credibility quotient test was used to verify the hypothesis $\mathrm{H}_{0}: \gamma=0$, that the tested distribution is better described by Gumbel distribution, against an alternative hypothesis $\mathrm{H}_{1}$ : $\gamma \neq 0$, that the tested distribution is better tested by other distributions of this family. The test statistics for this test is described with the formula: [26].

$$
T_{\mathrm{LR}}(x)=\frac{\prod_{i \leq n} g_{\hat{\gamma}, \hat{\mu}, \hat{\sigma}}\left(x_{i}\right)}{\prod_{i \leq n} g_{0, \tilde{\mu}, \tilde{\sigma}}\left(x_{i}\right)}
$$


From $(\hat{\gamma}, \hat{\mu}, \hat{\sigma})$ and $(\tilde{\mu}, \tilde{\sigma})$ representing the sets of the maximal likelihood estimators in the EV0, EV1 and EV2 models described by the formula (4). Since the sets of parameters are 2- and 3-dimensional, it is known that the test statistic has an asymptotically chi - square with 1 degree of freedom. Consequently, $\mathrm{p}$ - value has the formula:

$$
p_{\mathrm{LR}}(x)=1-\chi_{1}^{2}\left(T_{\mathrm{LR}}(x)\right)
$$

The significance level is achieved with higher accuracy using the Bartlett's adjustment (Hosking 1984), which consists in replacing the TLR test statistics with the statistics given by the formula $\mathrm{T}_{\mathrm{LR}} /$ $(1+2.8 / \mathrm{n})$. In this case, the $\mathrm{p}-$ value has the formula (9).

\section{Modelling the Distributions of Quarterly Hydrometric Parameters Maxima for the Studied Areas}

\section{Hydrometric data}

The study in this paper utilizes one of the hydrometric parameters, namely, the level of water [32]. For the purposes of the study, daily water level measurements were collected for the Nysa Kłodzka river taken from a water gage in the hydrological station located in Bystrzyca Kłodzka in the period from 01.01.1981 to 31.12.2011 which gives a sample size of $\mathrm{n}=11322$ and for the Kwisa river measured at the water gage in the hydrological station in the village of Leśna from the period from 01.01.1982 to 31.12.2011 which, in this case, gives a sample size of $n=10$ 957. The studied periods have been divided into three parts. In the case of data for the Kwisa river the period I spans over the years 1982 - 1991, the period II spans over the years of 1992 - 2001 and the period III spans over the years 2002 to 2011. In contrast, for the data from the Nysa Kłodzka river the period I spans the years 1981 - 1990, the period II spans over the years of 1991 - 2000 and the period III spans over the years 2001 to 2011. As can be noted the period III for the Nysa Kłodzka river is an 11 year period. The remaining periods for both surveyed locations are 10 year periods.

By using the block method, as described in the previous section, the quarterly highs of the daily water levels collected in two hydrological stations were selected.

Consecutive quarters in a calendar year have an uneven number of days: 90, 91 and 92. For the purpose of the study, a simplification was made by assuming that each quarter has the length of 91 days. The differences arising from the simplification introduced into the probabilistic analyses are statistically insignificant.

The formula (1) for all three periods studied in the Leśna village and for the first two periods in Bystrzyca Kłodzka takes the form:

$$
y_{i}=\max \left\{x_{i 1}, \ldots, x_{i 91}\right\}, i=1, \ldots, 40
$$

While for the data from the third period in Bystrzyca Kłodzka it takes the form:

$$
y_{i}=\max \left\{x_{i 1}, \ldots, x_{i 91}\right\}, i=1, \ldots, 44
$$

\section{Empirical and theoretical probability distributions for the quarterly maxima of the daily water levels}

The empirical function of probability density given by the formula (6) with optimally matched functional $\mathrm{k}$ and parameter $\mathrm{b}$ was used to graphically depict the empirical distributions of quarterly maxima of the studied characteristics in the three periods for each of the two areas. Additionally, each graph presents the function of probability density of the theoretical distribution optimally matched to the empirical distribution of the studied maxima. The charts referred to above are presented in Figures 1 and 2.

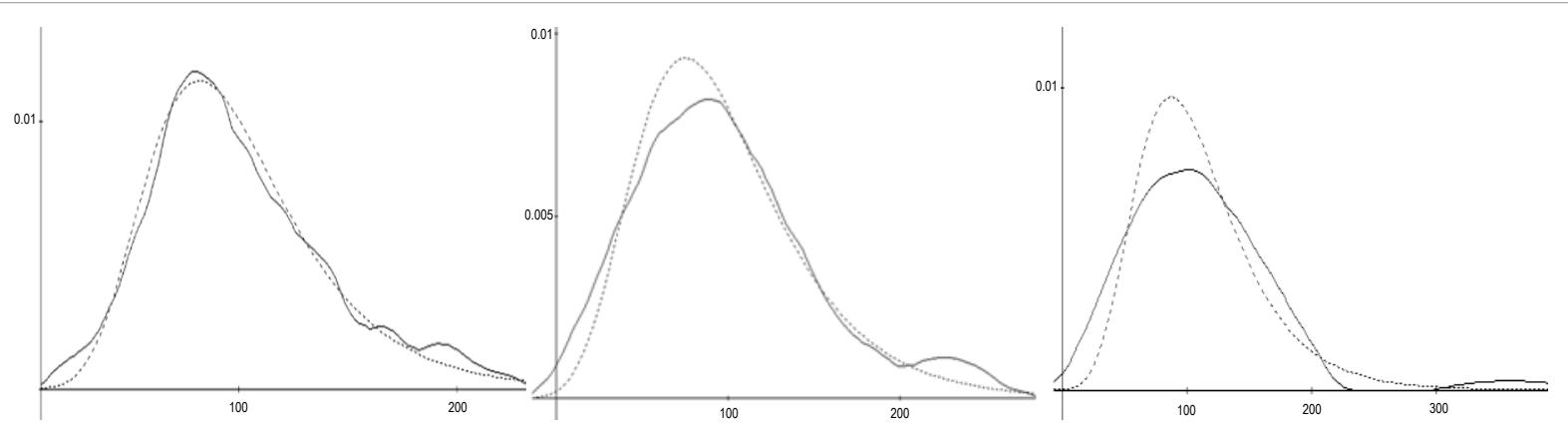

Figure 1: The empirical functions of distribution density of the quarterly water level maxima for the data from Bystrzyca Kłodzka for the periods I - III (solid line) and optimally matched theoretical distributions for quarterly maxima (dotted line). The chart on the left - the period I, the graph in the middle - the period II and the graph on the right - the period III. (Source: own materials).
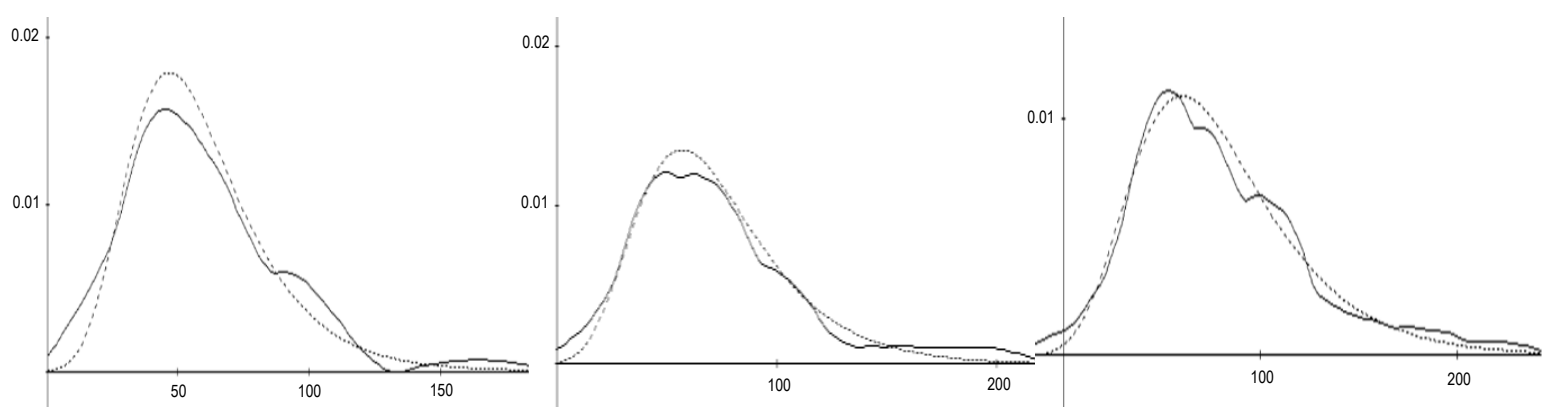

Figure 2: The empirical functions of distribution density of the quarterly water level maxima for the data from Leśna for the periods I - III (solid line) and optimally matched theoretical distributions for quarterly maxima (dotted line). The chart on the left - the period I, the graph in the middle - the period II and the graph on the right - the period III. (Source: own materials). 
By using the highest likelihood method the parameters of theoretical distributions optimally suited to the empirical distributions of quarterly daily water level maxima for the three analysed periods in the two measurement points: Bystrzyca Kłodzka and Leśna. The values of the $\mu$ position and $\sigma$ scale parameters for the theoretical distributions for the data from Bystrzyca Kłodzka and Leśna are presented in Table 1 and Table 2 respectively.

Presented below are the formulas of distribution functions for the distributions of the quarterly water level maxima for each of the three studied periods in the cases of the Nysa Kłodzka and the Kwisa. After the research, for all three periods studied, at the measurement point in Leśna and at the measuring point in Bystrzyca Kłodzka, the EV0 distribution (the Gumbel model) was proven to be optimally matched theoretical distribution, whose cumulative distribution is represented by the formula (4). The formulas of the distribution functions for the measurement point in Bystrzyca Kłodzka including the parameter estimators from Table 1:

\begin{tabular}{|c|l|}
\hline Periods & \multicolumn{1}{|c|}{ The estimator values } \\
\hline $1981-1990$ & $\hat{\mu}_{I}=82.02 \hat{\sigma}_{I}=31.87$ \\
\hline $1991-2000$ & $\hat{\mu}_{I I}=87.14 \hat{\sigma}_{I I}=37.9$ \\
\hline $2001-2011$ & $\hat{\mu}_{I I I}=75.29 \hat{\sigma}_{I I I}=45.41$ \\
\hline Source: Own materials & \\
\hline
\end{tabular}

Source: Own materials.

Table 1: The values of the $\mu, \sigma$ parameters estimates of the theoretical distributions for the Nysa Kłodzka river.

\begin{tabular}{|c|l|}
\hline Periods & \multicolumn{1}{|c|}{ The estimators values } \\
\hline $1982-1991$ & $\hat{\mu}_{I}=46.92 \hat{\sigma}_{I}=20.59$ \\
\hline $1992-2001$ & $\hat{\mu}_{I I}=56.9 \hat{\sigma}_{I I}=27.34$ \\
\hline $2002-2011$ & $\hat{\mu}_{I I I}=60.17 \hat{\sigma}_{I I I}=33.67$ \\
\hline
\end{tabular}

Source: Own materials.

Table 2: The values of the $\mu, \sigma$ parameters estimates the theoretical distributions for the Kwisa river.

\begin{tabular}{|c|c|c|}
\hline Test Period & K-S & A - D \\
\hline $1981-1990$ & $\mathrm{p}_{\mathrm{v}}=0.7035$ & $\mathrm{p}_{\mathrm{v}}=0.9138$ \\
\hline $1991-2000$ & $\mathrm{p}_{\mathrm{v}}=0.4807$ & $\mathrm{p}_{\mathrm{v}}=0.4417$ \\
\hline $2001-2011$ & $\mathrm{p}_{\mathrm{v}}=0.6913$ & $\mathrm{p}_{\mathrm{v}}=0.8515$ \\
\hline
\end{tabular}

Source: Own materials.

Table 3: The $p$ - value of the probability distributions, compatibility tests of the quarterly water level maxima in the three periods studied for the Nysa Kłodzka river.

\begin{tabular}{|c|c|c|}
\hline Test Period & K-S & A - D \\
\hline $1982-1991$ & $\mathrm{p}_{\mathrm{v}}=0.4032$ & $\mathrm{p}_{\mathrm{v}}=0.7107$ \\
\hline $1992-2001$ & $\mathrm{p}_{\mathrm{v}}=0.2662$ & $\mathrm{p}_{\mathrm{v}}=0.5857$ \\
\hline $2002-2011$ & $\mathrm{p}_{\mathrm{v}}=0.4281$ & $\mathrm{p}_{\mathrm{v}}=0.7331$ \\
\hline
\end{tabular}

Source: Own materials.

Table 4: The $p$ - value values of the probability distributions, compatibility tests of the quarterly water level maxima in the three periods studied for the Kwisa river.

\begin{tabular}{|c|c|c|c|}
\hline Periods & $\mathbf{p}_{\mathbf{v}}$ NysaKłodzka & Periods & $\mathbf{p}_{\mathbf{v}}$ Kwisa \\
\hline $1981-1990$ & 0.7468 & $1982-1991$ & 0.5897 \\
\hline $1991-2000$ & 0.3244 & $1992-2001$ & 0.3628 \\
\hline $2001-2011$ & 0.9195 & $2002-2011$ & 0.904 \\
\hline
\end{tabular}

Source: Own materials.

Table 5: The $p$-value values for the likelihood ratio test in the family for the family of extreme values distributions.

$$
\begin{aligned}
& 1981 \text { - } 1990 \text { period: } G_{0, \mu, \sigma}(x)=\exp \left(-e^{-(x-82.02) / 31.87}\right) \\
& 1991 \text { - } 2000 \text { period: } G_{0, \mu, \sigma}(x)=\exp \left(-e^{-(x-87.14) / 37.9}\right) \\
& 2001 \text { - } 2011 \text { period: } G_{0, \mu, \sigma}(x)=\exp \left(-e^{-(x-75.29) / 45.41}\right)
\end{aligned}
$$

The formulas of the distribution functions for the measurement point in Leśna including the parameter estimators from Table 2:

$$
\begin{aligned}
& 1982 \text { - } 1991 \text { period: } G_{0, \mu, \sigma}(x)=\exp \left(-e^{-(x-46.92) / 20.59}\right) \\
& 1992 \text { - } 2001 \text { period: } G_{0, \mu, \sigma}(x)=\exp \left(-e^{-(x-56.9) / 27.34}\right) \\
& 2002 \text { - } 2011 \text { period: } G_{0, \mu, \sigma}(x)=\exp \left(-e^{-(x-60.17) / 33.67}\right)
\end{aligned}
$$

The charts of empirical density functions of probability distributions of the quarterly maxima for the analysed periods and locations along with the probability density functions of the corresponding theoretical distributions show a very good match of some theoretical distributions (Figures 1 and 2).

In order to confirm the goodness of fit of the empirical distributions with the matched theoretical distributions resulting from a visual assessment of the probability distribution function graphs two commonly used tests were performed: Anderson-Darling test and Kolmogorov-Smirnov test. The test results for the distribution of the three periods of two locations in the form of p-value shown in Tables 3 and 4 confirm a very high goodness of fit of the selected theoretical distributions with the corresponding empirical distributions.

In addition, to confirm a very high goodness of fit of the theoretical distributions selected on the basis of visual charts with the empirical and theoretical probability distributions a likelihood ratio test was performed within the family of distributions for extreme values described in detail in Section 3.3. The values of $\mathrm{p}$-value calculated using the formula (9) for all distributions in the examined periods and points of measurement are included in Table 5. The test results confirm the validity of the use of the Gumbel distribution to model the distribution of quarterly maxima of the studied hydrometric parameter in each of the cases.

\section{Analysis of the Flood Risk Dynamics on the Kwisa and the Nysa Kłodzka Rivers}

This section consists of two main parts. In the first part, flood risk measures will be calculated in the periods studied for the two measuring points. The second part of the chapter is solely devoted to the analysis of the dynamics of the flood risk in the analysed periods.

Defining the concept of risk proves to be a difficult time every time. Providing a clear, precise definition is impossible. Risk is defined on the basis of various branches of knowledge and theories, including economics, behavioural sciences, legal sciences, psychology, statistics, insurance, probability theory and others. According to the authors, the following two definitions of risk are most suitable to determine the flood risk. The first one treats risk as the possibility or likelihood of loss, e.g. Due to flooding $[33,34]$. The second definition assumed risk to be the probability of a system failure or the failure of its element $\mathrm{p}_{\mathrm{f}}$, which, in the particular cases, may be equated with flooding [35].

In this paper, based on the aforementioned two definitions, the probability of exceeding a certain water level $(\mathrm{u})$ by the maximal daily water level from the time horizon assumed in the study was adopted as the measure of the flood risk on a given area. In the case in this work, a quarter (91 days) was adopted as the time horizon. The water level, which was used to calculate the flood risk measures in the periods studied in both areas is the emergency level set for the studied hydrological stations [36,37]. 


\begin{tabular}{|c|c|c|c|}
\hline $\begin{array}{c}\text { Risk measure } \\
\text { Periods }\end{array}$ & $\mathbf{P}\left(\mathbf{M}_{\mathbf{N K}, 91}{\left.\mathbf{~} \mathbf{u}_{\mathbf{N K}}(\mathbf{A})\right)}\right.$ & $\begin{array}{c}\text { Dynamics } \\
\text { indexes }_{\text {ttt-1 }}\end{array}$ & $\begin{array}{c}\text { Percentile } \\
\text { changes +/- }\end{array}$ \\
\hline I: $1981-1990$ & 0.0452 & - & - \\
\hline II: $1991-2000$ & 0.0827 & 1.8296 & 82.96 \\
\hline III: $2001-2011$ & 0.0949 & 1.1475 & 14.75 \\
\hline Source: Own materials & & & \\
\hline
\end{tabular}

Table 6: Measures of flood risk for the Nysa Kłodzka river.

\begin{tabular}{|c|c|c|c|}
\hline $\begin{array}{c}\text { Risk measure } \\
\text { Periods }\end{array}$ & $\mathbf{P}\left(\mathbf{M}_{\mathbf{K}, 91}{\left.\mathbf{~} \mathbf{u}_{\mathbf{k}}(\mathbf{A})\right)}^{\text {Dynamics }}\right.$ & $\begin{array}{c}\text { Percentile } \\
\text { indexes }_{\text {ttt-1 }}\end{array}$ & changes +/- \\
\hline I: $1982-1991$ & 0.0731 & - & - \\
\hline II: $1992-2001$ & 0.1876 & 2.5663 & 156.63 \\
\hline III: $2002-2011$ & 0.2639 & 1.4067 & 40.67 \\
\hline Source: Own & & & \\
\hline
\end{tabular}

Table 7: Measures of flood risk for the Kwisa river.

The emergency levels for the Nysa Kłodzka river in the hydrological station in Bystrzyca Kłodzka and for the Kwisa river in the hydrological station in the Leśna village are as follows: $\mathrm{u}_{\mathrm{NK}}(\mathrm{A})=180 \mathrm{~cm}$ and $\mathrm{u}_{\mathrm{K}}(\mathrm{A})$ $=100 \mathrm{~cm}$.

According to the formula (2) the maximal quarterly water level is a random variable marked as $\mathrm{M}_{91}$. For the measurement point on the Nysa Kłodzka river this variable is marked as $\mathrm{M}_{\mathrm{NK}, 91}$ while for the measurement point on the Kwisa river as $\mathrm{M}_{\mathrm{K}, 91}$. Tables 6 and 7 present the results of calculations of the risk measure or the probability of exceeding the emergency level by the random variables $M_{\mathrm{NK}, 91}$ and $\mathrm{M}_{\mathrm{K}, 91}$ for all the studied periods.

Additionally, Tables 6 and 7 contain the indexes of flood risk changes dynamics in the studied period in the two study areas. The results show that the trend is clearly increasing in both studied locations. On the Nysa Kłodzka river, in the measurement station in Bystrzyca Kłodzka, the risk of flooding during the period II was $82.96 \%$ higher than in the period I, while in the period III the risk was higher by $14.75 \%$ than in the period II. On the Kwisa river, in the studied period, the risk is characterized by higher dynamics. During the period II, the flood risk was even $156.63 \%$ higher than in the period I, while in the period III the risk was $40.67 \%$ higher than in the period II.

In the two studied points, the dynamics of changes in flood risk varies. At the measurement point on the Kwisa river, in the hydrological station in the Leśna village, this dynamics is clearly higher. There are many factors influencing this situation, but this issue will not be addressed in this article. Despite the differences in the risk dynamics in both locations during the studied period proportionality of changes of the flood risk can be seen in both areas. In both studied points the increase during the period II in comparison to period I is significantly higher than in period III compared to the period II [38-41].

\section{Conclusions}

The temporal and spatial analysis of the change dynamics of the flood risk in the studied measurement points indicates growth trends of the flood risk in the described time horizons. At the measuring point for the Kwisa river at the gage Leśna ( $\mathrm{km}$ of the river according to RZGW $-89+230, \mathrm{~km}$ according to IMGW-86+600) as well as for the gage Bystrzyca Kłodzka on the Nysa Kłodzka river (in km of the river according to RZGW $-151+438, \mathrm{~km}$ of the river according to IMGW $-147+800)$ the risk dynamics in $1991-2000$ period compared to the 1981-1990 period was higher than in comparison with the 2001-2011 period. As a result of the assumed train of thought and the conducted analyses, the authors conclude that the hard and soft actions to minimize the flood risks until now have been insufficient. The current actions should therefore be carried out on the basis of the risk measures based on the results of the monitoring network. On the basis of the risk measures the authors suggest the development of indicators that should be included in such programs as ISOK and in dynamic and static flood models. Spatial planning must take the levels of the flood risk into account by defining the technical conditions for buildings, security systems for people and institutions.

\section{References}

1. Łach J (2009) The history of floods on the ground Kłodzko and their influence on the direction of the transformation dendolinnych Nysa Kłodzka and White Lądecka, Nature Science Technology. Volume 3: 3.

2. Nowak Z (2001) Environmental management, part-I. Gliwice: Silesian University of Technology.

3. Gumbel E (1954) Statistical theory of extreme values and some practical applications, National Bureau of Standards, Applied Mathematics Series, Vol. 33.

4. Bortkiewicz L (1992) Mean variation and error. Sitzungsber Berli MethGoose-5.

5. Gumbel E (1941) The return period of flood flaws. Ann Math Statist- 5.

6. Gumbel E (1944) On the plotting of flood discharges, Trance. Amer. Geophys Union 25: 699-719.

7. Gumbel E (1945) Floods estimated by probability methods. Engrg NewsRecord 134: 97-101.

8. Gumbel E (1948) The statistical forecast of floods. Water Resources Board Bulletin No. 5.

9. Todorovic P (1978) A probabilistic approach to analysis and prediction of floods. Proc. 43rd ISI.

10. Pericchi L, Rodriguez-Iturbe I (1985) On statistical analysis of floods, In Celebration Statistics, A. Fienberg, S. Atkinson, (eds.) 511-541.The IS Centenary Volume.

11. Greis N, Wood E (1981) Regional flood frequency estimation and network design. Water Resources Res 1167-1177.

12. Shen H, Bryson M, Ochoa I (1980) Effect of tail behavior assumptions on flood, Water Resources Re. 16: 361-364.

13. Rossi F, Fiorentino M, Versace P (1986) Two - component extreme value distribution for flood frequency analysis. Water Resources Res. 22: 1551-1564.

14. Smith R (1987) Estimating the upper tail of flood frequency distributions, Water Resources Res. 23: 1657-1666.

15. Ahmad M, Sinclair C, Spurr B (1998) Assessment of flood frequency models using empirical distribution function statistics. Water Resources Res. 5.

16. Hipel K (1994) Extreme values: Floods and droughts, Proceedings of International Conference on Stochastic and Statistical Methods in Hydrology and Environmental Engineering Vol 1. Kluwer, Dordrecht.

17. Katz R, Parlange M, Neveau P (2002) Statistics of extremes in Hydrology Advances in Water Resources: 8-12.

18. Engeland K, Frigessi A, Hisdal H (2005) Practical extreme value modeling of hydrological floods and droughts: A Case Study. Extremes 7: 5-30.

19. Bordi I, Fraedrich K, Petitta M, Sutera A (2006) Extreme value analysis of wet and dry periods in Sicily. Theor Appl Climatol 5.

20. Dogan A, Haktanir T, Seckin S, Yurtal R (2010) Comparison of probability weighted moments and maximum likelihood methods used in frequency analysis for Ceyhan river basin. Arabian J Sci \& Eng 35 Issue 1B: 49-69.

21. Holičky M, Sykora M (2010) Assessment of flooding risk to cultural heritage in historic sites. Journal of performance of constructed facilities: 432-438.

22. Nachaben M, Paynter S (2011) Use of generalized extreme value covariates to improve estimation of trends and return frequencies for lake levels. Journal of Hydro-informatics 13.1: 13-24.

23. Chaibandit K, Konyai S (2012) Using statistics in hydrology for analyzing discharge of the Yom river, APCBEE Procedia-1.

24. Arns A, Wahl T, Jensen IJ, Pattiaratchi C (2013) Estimating extreme water leve probabilities: A direct comparison of the methods and recommendations for best practice. Coastal Eng 81: 51-66. 
25. Charon C (2015) Probability distributions of wind speed in the UAE. Energy Conversion and Manage $93: 414-434$

26. Thomas M, Reiss R (2007) Statistical analysis of extreme value with applications to insurance, finance, hydrology and other fields. Basel: Birkhauser.

27. Kuźmiński L (2013) Limit distribution function of extreme values for dependent random variables, Econometrics. Publishing House of the University of Economics in Wroclaw. 2: 29.

28. Yue S, Bobe B, Legendre P, Bruneau $P$ (1999) The Gumbel mixed model for flood frequency analysis. J Hydrol pp: 88-100.

29. Leadbetter M, Lindgren G, Rootzen H (1983) Extremes and related properties of random sequences and processes, New York, Springer-Verlag.

30. Kotz S, Nadarajah S (2005) Extreme value distributions. Theory and applications. London: Imperial College Press.

31. Smith R (1985) Maximum likelihood estimation in a class of non-regular cases. Biometrika. pp: 69-90.

32. Bajkiewicz-Grabowska E, Mikulski Z (2011) Hydrology general. Warsaw: PWN

33. Jedynak $P$ (2001) Limit distribution function of extreme values for dependent random variables, Insurance economy. Selected elements of theory and practice.

34. Kunreuther H, Roth R (1998) Paying the price, Washington, Joseph Henry Press.

35. Yen B (1988) stochastic methods and reliability analysis in water resources Advances Water Resources, Vol. 11.

36. Beran M, Hoskin J, Arnell N (1996) Comment on two - component extreme value distribution for flood frequency analysis. Fabio Rossi, Mauro Fiorentino, Pasquale Versace, (eds.) Water Resources Res. 5.

37. Fuller W (1914) Floods flows. Trance Amer Soc, Civil Engineers 77: 564-583.

38. Hosking $J$ (1984) Testing whether the shape is a zero in the generalized extreme value distribution, Biometrika 71: 367-374.

39. http://mapy.isok.gov.pl/imap/

40. Jain D, Singh V (1987) Estimating parameters of EV1 distribution for flood frequency analysis, Water Resources Res. 5.

41. https://wroclaw.rzgw.gov.pl/en/index 